\title{
Upgrade of the B2G dynamic geothermal heat exchanger model: optimal location of the ground nodes
}

\section{Antonio Cazorla-Marín Francesco Tinti}

\author{
Carla Montagud \\ Sara Focaccia
}

\author{
José M. Corberán
}

\begin{abstract}
In order to optimize the design and operation of a ground source heat pump system, the modeling of the Borehole Heat Exchanger (BHE) and its coupling to the heat pump operation becomes crucial. This becomes key for those systems with on/ off operation, where it is important to model the short-term response of the BHE accurately. Furthermore, the modeling of the local variation of the ground temperature near the BHE will be highly influenced by ground thermal properties and the operation of the system. In this context, the novel B2G dynamic model was developed and experimentally validated in previous works for a single U BHE and adapted to a novel coaxial spiral configuration. In order to consider the influence of the soil surrounding the BHE, two ground nodes were initially defined and their position (penetration radii) was calculated for a specific type of soil and operating conditions. This paper presents an upgrade of the B2G model, with a descripton of penetration radii calculation. For this purpose, a comparison between the B2G model and the Infinite Cylindrical Source model was carried out to find the penetration radii that reproduce the ground thermal response with a higher accuracy under the corresponding soil thermal properties and operating conditions.
\end{abstract}

\section{INTRODUCTION}

During the last years, the concern about the global warming and the environmental pollution has lead to the research and widespread of renewable energy sources, together with an increase in the efficiency of the energy systems, with the aim of reducing the carbon emissions and reduce the global pollution. In the sector of heating and cooling in buildings, the Ground Source Heat Pump (GSHP) systems represent an efficient alternative to conventional systems (Rees 2016). In these systems, the ground is used in order to provide heat to the system (heat source) or to store the heat injected by the system (heat sink). This heat exchange with the system is performed by the use of a Borehole Heat Exchanger (BHE) field. Inside the BHE, the flowing fluid is heated up or cooled down because of the temperature difference between the surrounding ground and the fluid. In order to assist in the design of the BHEs and the optimal control of GSHP systems, an accurate dynamic model is a helpful tool, being able to reproduce the thermodynamic behavior of the BHE itself and then, couple the BHE model to the rest of the components inside an integrated system model. However, in order to reproduce the BHE behavior accurately, it is important to model not only the long-term response of the BHE and the surrounding ground, but also the short-term. This is especially important in systems with an on/off operation, where the accurate reproduction of the short-term response of the BHE becomes crucial. For this 
purpose, the temperature variation of the nearer surrounding ground must be well predicted, and it will depend not only on the heat injected or extracted, but also on the ground thermal properties and the operating conditions of the BHE.

In this framework, several BHE models have been developed along the years. Some of them are focused on the prediction of the ground temperature variation under different assumptions, for example, the commonly used analytical models Infinite Line Source (ILS), Infinite Cylindrical Source (ICS) or Finite Line Source (FLS) based on the work carried out by Carslaw and Jaeger (1959). On the other hand, there exist several models with a higher level of detail, able to reproduce also the behavior inside the borehole in terms of water temperature. The analytical models usually include some assumptions and simplifications in order to reduce the computational cost, but also reducing the precision. However, they are easier to couple with other simulation programs (Yang, et al. 2010). Among these models, several of them use a thermal network based on thermal resistances and capacitances in order to model the heat transfer between the borehole and the surrounding ground (Eskilson and Claesson 1988; Yang, et al. 2012; Bauer, et al. 2011; Pasquier and Marcotte 2012; Lamarche, et al. 2010). Furthermore, some short-term analytical solutions have been developed, for example the one developed by Li and Lai (2012). However it can be used in time scales higher than one hour (to several years), not in vey short-term scales (in the range of minutes) in order to reproduce the dynamic behavior of an on/off GSHP. On the other hand, there exist several numerical models (Al-Khoury 2012) with a higher level of flexibility and more accuracy, but also with a higher computational cost, being difficult to couple them with other energy analysis programs. Furthermore, some other computer programs are used in the design and simulation of GSHP systems and the BHE, for example: GLHEPRO, EED, EnergyPlus or TRNSYS (Yang, et al. 2010). Regarding the thermal response of the ground and the amount of soil that is affected by the heat injection during a specific time period, it is usually addressed by adding a number of radial ground nodes and discretizing the soil mass in small radial steps until the farfield radius, where the effect of the heat injection vanishes. This far-field radius calculation has been addressed by several authors, for example, Hart and Couvillion (1986) defined it as $r_{\infty}=4 \sqrt{\alpha t}$, which depends on the ground thermal diffusivity $(\alpha)$ and the injection period $(t)$. The addition of ground nodes inevitably leads to an increase in the complexity of the model and therefore, an increase in the computational cost. In this context, the novel B2G dynamic model was developed and experimentally validated in previous works for a single U BHE (Ruiz-Calvo, et al. 2015). In order to reduce the computational cost, the simpler $2 \mathrm{D}$ thermal network that reproduces the fluid temperature evolution with a high accuracy was used and only the portion of the surrounding ground affected by the heat injection period was considered. This model was adapted to a novel coaxial spiral BHE configuration designed by GEOTHEX® (http://www.geothex.nl/). This BHE has been developed and optimized in the framework of a HORIZON 2020 European Project, GEOTeCH (European Commision 2015). The adaptation to the coaxial spiral BHE was previously presented in the IGSHPA 2017 conference (Cazorla-Marin, et al. 2017a), where a validation of the model with experimental data from a TRT (Witte 2012) was carried out. In order to account for the influence of the thermal properties of the ground and the operating conditions of the system in the soil surrounding the BHE wall, two different penetration diameters were initially defined as an input in the model (now referred as penetration radii). They were determined calculating the distance at which the heat transfer rate in the ground was negligible by using the ICS model for the specific type of soil and different injection times, for example, 15 hours for the second ground node (mid-term) and 3 hours for the first ground node (short-term). The results showed that the B2G approach applied to this configuration produced a model that could accurately predict the behaviour of the BHE, obtaining a Root Mean Square Error (RMSE) of $0.095 \mathrm{~K}$ (in the case with no enhanced convective heat transfer). In this work, an upgrade of the B2G model with three ground nodes is presented. The simulation in TRNSYS with the same TRT data produces a RMSE of $0.088 \mathrm{~K}$, lower than the previous work. In order to make the use of the B2G model more general, it should be able to reproduce the effect of any type of soil and system operating conditions. Therefore, their influence in the determination of the corresponding penetration radii needs to be addressed and modelled. This paper presents an upgrade of the B2G model where the determination of the ground nodes location is described. For this purpose, the B2G model was compared to the ICS model, and the penetration radii that minimize the difference between the results of the two models is calculated by using an optimization algorithm implemented in MATLAB ${ }^{\circledR}$. The future objective of this 
methodology is to obtain polynomial correllations where the penetration radii could be determined as a function of the soil thermal properties, BHE geometry and operating conditions (heat injection period). These correlations would be further implemented inside the B2G model for its widespread use.

\section{B2G BHE MODEL}

\section{U-tube B2G model}

The B2G dynamic model was originally developed in order to reproduce the short-term behaviour of a single Utube $\mathrm{BHE}$ in terms of the water temperature evolution throughout the pipe. For this purpose, a thermal network approach is used, together with a vertical discretization of the borehole. In order to reduce the computational cost, a simple 2D thermal network was used and only the portion of the surrounding ground affected by the heat injection/extraction was considered, so that it is possible to reproduce the water temperature evolution with a high accuracy. The thermal network consists of five nodes, connected by six thermal resistances, where each node represents one part of the BHE: downward and upward fluid, two grout sections and the surrounding ground. The thermal properties of the fluid, grout and ground are considered: thermal capacitance (representing the thermal inertia) and conductivity, as well as the BHE geometry. On the other hand, the thermal resistances represent the convective and conductive heat transfer between nodes. Concerning the fluid nodes, the advection is taken into account, but the axial conduction is neglected. The entire model consists of a 5C6R-n model (five thermal capacitances, six thermal resistances and $n$ vertical divisions of the BHE), which is a system of ordinary differential equations that is solved by standard numerical procedures. The U-tube B2G model was implemented in TRNSYS and was presented and experimentally validated against different conditions in (Ruiz-Calvo, et al. 2015) and (De Rosa, et al. 2015).

\section{Coaxial B2G model}

The single U-tube BHE model was adapted to a standard coaxial configuration as well as to a spiral coaxial configuration. The main difference between them is that, in the spiral coaxial BHE, the fluid flowing through the outer pipe follows a helical path. This is modeled using an equivalent section in the outer pipe, that is, the equivalent hydraulic diameter corresponding to the helical channel is determined in order to calculate the hydraulic and thermodynamic properties. The adaptation of the B2G model to the standard coaxial configuration was previously presented in (CazorlaMarin, et al. 2017b). On the other hand, the adaptation to the spiral coaxial configuration was presented in (CazorlaMarin, et al. 2017a), where a more detailed explanation of the model and the calculation of the different parameters can be found, this description is also applicable to the standard coaxial configuration. In order to adapt the B2G model to the coaxial configurations, the thermal network was modified to a simpler linear thermal network with five thermal capacitances and four thermal resistances. Furthermore, the vertical heat conduction between grout and ground nodes is considered by the use of vertical thermal resistances $\left(R_{v b}, R_{v g 1}\right.$ and $\left.R_{v g 2}\right)$. The five thermal capacitances represent the fluid in the inner pipe $\left(T_{i}\right)$, the fluid in the outer pipe $\left(T_{o}\right)$, the grout $\left(T_{b}\right)$, the closer surrounding ground $\left(T_{g 1}\right)$, which represents the ground affected by a short period of heat injection/extraction and a further ground section $\left(T_{g 2}\right)$, representing the ground affected by a larger period of heat injection/extraction. The convective and conductive heat transfer between nodes was calculated using radial thermal resistances between nodes $\left(R_{i o}, R_{o b}, R_{b g 1}\right.$ and $\left.R_{g 1 g 2}\right)$. As it can be observed, in the coaxial model, two ground nodes are used instead of only one. In this way, it is possible to obtain a better prediction of the ground temperature evolution during all the heat injection/ extraction period, therefore, a better accuracy in the prediction of the fluid temperature. In the last version of the coaxial model, another ground node has been added, representing the undisturbed ground $\left(T_{u g}\right)$, where the temperature is constant. Therefore, it is possible to take into account the heat transfer between the second ground node and the undisturbed ground, represented

by a thermal resistance $\left(R_{g 2 u g}\right)$, as it is presented in (Cazorla-Marin, et al. 2018). Figure 1 a) shows the linear thermal network for the spiral coaxial model, while the vertical discretization of the borehole is shown in Figure $1 \mathrm{~b}$ ). 

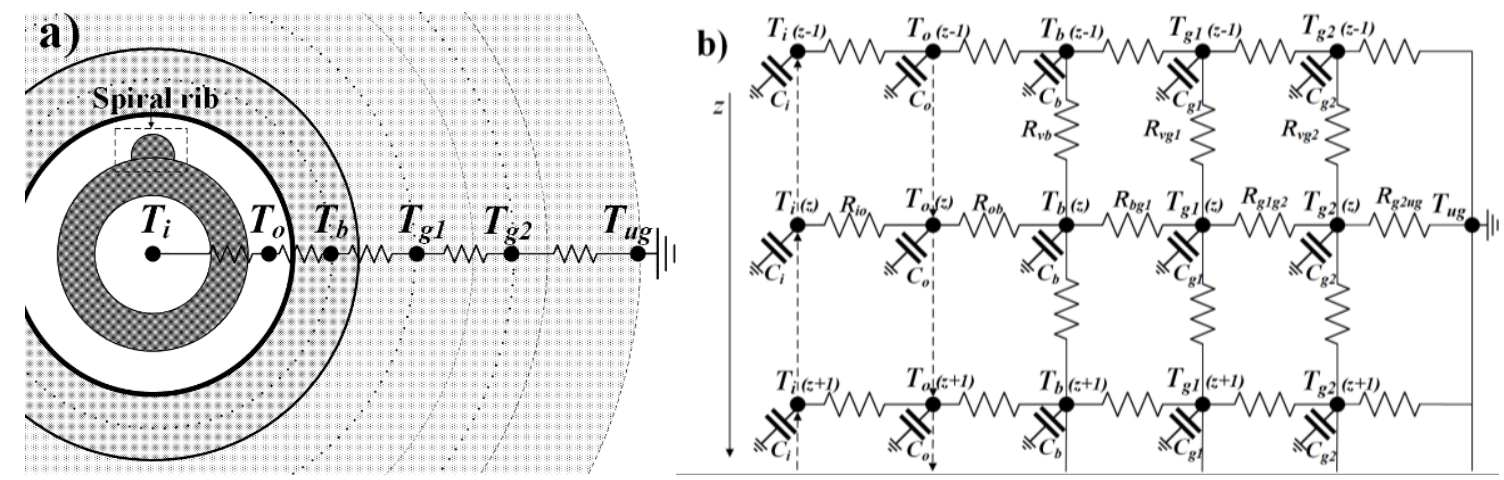

Figure 1 Thermal network of the coaxial configuration model: a) borehole layout (spiral coaxial); b) vertical discretization.

\section{OPTIMAL LOCATION OF THE GROUND NODES}

The position of the ground nodes is defined by three penetration radii. The calculation of these penetration radii is not straitghforward, as it will influence in the calculation of the ground temperature and thus, in the water temperature calculation. For example, for the first ground node, the higher the value of the penetration radius, the bigger the amount of ground that the model will consider, therefore, the bigger the heat capacity of this ground section. If the heat capacity is bigger, the temperature of this node will vary slowlier, and it will influence in the short-term evolution of the water temperature. Analogously, the same will occur with the second ground node. However, the position of the undisturbed ground node will only have an influence in the heat transfer between the second ground node and the undisturbed ground node (increasing or decreasing the thermal resitance), as it only represents a temperature boundary, with no temperature variation. In previous works, in order to calculate the radius of the undisturbed ground node $\left(R_{u g p}\right)$, the heat flux in the ground was calculated for the whole heat injection period in the radial direction, and the distance where the heat flux was negligible for this period was used to set the undisturbed ground node distance. For this purpose, the equation of the Infinite Cylindrical Source (ICS) (Carslaw and Jaeger 1959) model was used. Regarding the other ground nodes, their position was calculated for a shorter period of heat injection (for example, 1 hour for the first ground node and 5 hours for the second ground node). In this work, a new methodology is proposed, in which a comparison between the B2G model and the ICS model is carried out in order to calculate the penetration radii that reproduce with the highest accuracy the temperature variation of the ground nodes and the heat transfer along the ground. In this comparison, a constant heat flux on the borehole wall during all the heat injection period is assumed, and the ground temperature variation is calculated for the ground nodes position and the heat transfer rate between them, for each time step. The ground nodes position (penetration radii $R_{g p 1}, R_{g p 2}$ and $R_{u g}$; corresponding to the ground nodes $T_{g 1}, T_{g 2}$ and $T_{u g}$, respectively) will be optimized, so the difference between the results calculated by the two models is minimum. For this purpose, the B2G thermal network has been adapted in order to consider a constant heat flux on the borehole wall instead of the fluid through the BHE tubes. Therefore, a node on this surface is considered $\left(T_{b}\right)$, and a constant heat flux $\left(q_{0}\right)$ is imposed. Figure 2 shows the thermal network corresponding to this problem. The ground nodes $T_{g 1}$ and $T_{g 2}$ are located, each one, at the average distance between the two concentric circumferences that form each annulus region. These positions are defined by the radii $r_{g 1}$ and $r_{g 2}$, respectively.

$$
r_{g 1}=\frac{R_{g p 1}+r_{b}}{2} ; r_{g 2}=\frac{R_{g p 2}+R_{g p 1}}{2}
$$

Where $r_{b}$ represents the borehole wall radius. On the other hand, $q_{1}$ represents the heat transfer between the ground nodes $T_{g 1}$ and $T_{g 2}$, while $q_{2}$ represents the heat transfer between $T_{g 2}$ and $T_{u g}$. 


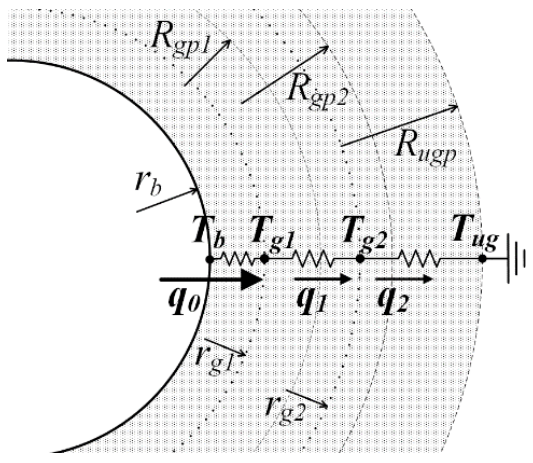

Figure 2 Thermal network used for the calculation of the penetration radii

The main parameters used in the models are the borehole radius $\left(r_{b}\right)$, the ground thermal conductivity $(\lambda)$, the ground volumetric heat capacity $\left(c_{v}\right)$ and the heat flux $\left(q_{0}\right)$. The main inputs are the three penetration radii $\left(R_{g p 1}, R_{g p 2}\right.$ and $R_{u g}$ ). The initial ground temperature is assumed to be zero, as only the temperature variation is calculated.

\section{B2G model}

In the B2G model, the temperature of the ground nodes $T_{g 1}$ and $T_{g 2}$ is calculated using the main BHE parameters and penetration radii. First, the thermal capacitances $(C)$ of the two ground nodes are calculated (eq. 2), together with the $U A$ values, which represent the thermal resistance between ground nodes (eq. 3).

$$
\begin{gathered}
C_{g 1}=\pi\left(R_{g p 1}^{2}-r_{b}^{2}\right) c_{v} \quad ; \quad C_{g 2}=\pi\left(R_{g p 2}^{2}-R_{g p 1}^{2}\right) c_{v} \\
U A_{b g 1}=\frac{2 \pi \lambda}{\ln \left(r_{g 1} / r_{b}\right)} \quad ; \quad U A_{g 1 g 2}=\frac{2 \pi \lambda}{\ln \left(r_{g 2} / r_{g 1}\right)} \quad ; \quad U A_{g 2 u g}=\frac{2 \pi \lambda}{\ln \left(R_{u g} / r_{g 2}\right)}
\end{gathered}
$$

Second, the ground nodes temperatures $\left(T_{g 1}\right.$ and $\left.T_{g 2}\right)$ are calculated using the energy balance equations. The undisturbed ground temperature is defined as zero $\left(T_{u g}=0\right)$.

$$
\begin{gathered}
C_{g 1} \frac{\partial T_{g 1}(t)}{\partial t}=q_{0}+U A_{g 1 g 2}\left(T_{g 2}(t)-T_{g 1}(t)\right) \\
C_{g 2} \frac{\partial T_{g 2}(t)}{\partial t}=U A_{g 1 g 2}\left(T_{g 1}(t)-T_{g 2}(t)\right)+U A_{g 2 u g}\left(T_{u g}(t)-T_{g 2}(t)\right)
\end{gathered}
$$

Finally, the heat transfer rate between ground nodes is calculated $\left(q_{1}\right.$ and $\left.q_{2}\right)$ using the equations 6 and 7 .

$$
\begin{aligned}
& q_{1}^{B 2 G}(t)=U A_{g 1 g 2}\left(\left(T_{g 1}^{B 2 G}(t)-T_{g 2}^{B 2 G}(t)\right)\right. \\
& q_{2}^{B 2 G}(t)=U A_{g 2 u g}\left(\left(T_{g 2}^{B 2 G}(t)-T_{u g}^{B 2 G}(t)\right)\right.
\end{aligned}
$$

\section{Infinite Cylindrical Source model}

The Infinite Cylindrical Source (ICS) model calculates the heat transfer in the region bounded internally by a 
circular cylinder and constant heat flux in its surface. In this case, the internal circular cylinder would correspond to the borehole wall, with radius $r_{b}$, and the constant heat flux through its surface would be $q_{0}$. The solution for the calculation of the ground temperature along the radial distance was provided by Carslaw and Jaeger (Carslaw and Jaeger 1959). This solution is presented in equation (8), where the initial ground temperature is zero, and $\alpha$ represents the thermal diffusivity of the ground $\left(\alpha=\lambda / c_{v}\right)$.

$$
T^{I C S}(r, t)=-\frac{2 q_{0}}{\pi^{2} r_{b} \lambda} \int_{0}^{\infty}\left(1-e^{-\alpha u^{2} t}\right) \frac{J_{0}(u r) Y_{1}\left(u r_{b}\right)-Y_{0}(u r) J_{1}\left(u r_{b}\right)}{\left.u^{2} J_{1}^{2}\left(u r_{b}\right)+Y_{1}^{2}\left(u r_{b}\right)\right]} d u
$$

Therefore, the temperature in the ground nodes will be calculated by the equation (9).

$$
T_{g 1}^{I C S}(t)=T^{I C S}\left(r_{g 1}, t\right) \quad ; \quad T_{g 2}^{I C S}(t)=T^{I C S}\left(r_{g 2}, t\right)
$$

Regarding the heat transfer between nodes, it is calculated using the Fourier's law applied in the frontier between the ground nodes $\left(R_{g p 1}\right.$ and $R_{g p 2}$ ), using the equations (10-11), where $\Delta r$ represents a very small radial distance.

$$
\begin{aligned}
q_{1}^{I C S}(t) & =-2 \pi R_{g p 1} \lambda \frac{T_{R_{g p 1}}^{I C S}(t)-T_{R_{g p 1}+\Delta r}^{I C S}(t)}{\Delta r} \\
q_{2}^{I C S}(t) & =-2 \pi R_{g p 2} \lambda \frac{T_{R_{g p 2}}^{I C S}(t)-T_{R_{g p 2}+\Delta r}^{I C S}(t)}{\Delta r}
\end{aligned}
$$

\section{Calculation and validation of penetration radii}

Both the B2G model and ICS were implemented in MATLAB and the Root Mean Square Error (RMSE) between the B2G results and the ICS is calculated for a set of penetration radii $\left(R_{g p 1}, R_{g p 2}\right.$ and $\left.R_{u g}\right)$. Therefore, it is possible to find the penetration radii that minimize the RMSE between the two models by using an optimization algorithm. In this case, a pattern search optimization methodology was used by using the solver patternsearch, already implemented in the Global Optimization Toolbox in MATLAB (MathWorks 2017). For the calculation, two approaches were used:

a) Ground nodes temperatures optimization. The ground nodes temperatures $T_{g 1}$ and $T_{g 2}$ are the variables calculated by each model. Therefore, the optimization solver calculates the set of radii that minimizes the RMSE between these temperatures calculated by the B2G and the ICS models.

b) Heat transfer rates optimization. The heat transfer rates $q_{1}$ and $q_{2}$ are the variables to calculate. Therefore, the optimization solver finds the penetration radii that minimize the RMSE between the heat transfer rates calculated by each model.

Once the penetration radii are calculated, they are used as inputs in the B2G model implemented in TRNSYS. Thus, it can be checked if this set of penetration radii are suitable to reproduce the behavior of the BHE accurately. For this purpose, it is employed the same methodology followed in (Cazorla-Marin, et al. 2017a), using the experimental data from a Thermal Response Test (TRT). So the inlet mass flow rate and fluid temperature are introduced as inputs in the B2G model and the outlet fluid temperature is calculated, together with the total heat transferred to the ground. Then, the calculated results are compared to the experimental ones by calculating the RMSE of the outlet fluid temperature and the percentage difference of the heat transferred to the ground.

\section{Case study parameters}

In this study, the spiral coaxial BHE developed by GEOTHEX® was used. The main parameters are calculated 
from a TRT carried out in Houten, The Netherlands (Witte 2012). The main parameters used in the calculation of the penetration radii in MATLAB are shown in Table 1. Regarding the main parameters used for the TRT simulation in TRNSYS, they are the same as the ones already presented in a previous work (Cazorla-Marin, et al. 2017a).

Table 1. Main parameters for the calculation of the penetration radii

\begin{tabular}{cccc}
\hline TRT data & \multicolumn{3}{c}{ Model parameters } \\
\hline \hline Ground thermal conductivity & $2.13 \mathrm{~W} / \mathrm{m} \cdot \mathrm{K}$ & Heat injection period & $15 \mathrm{~h}$ \\
Ground volumetric heat capacity & $2410 \mathrm{~kJ} / \mathrm{m}^{3} \cdot \mathrm{K}$ & Time step & $3 \mathrm{~min}$ \\
Borehole radius $\left(r_{b}\right)$ & $0.044 \mathrm{~m}$ & Differential radial distance $(\Delta r)$ & $0.001 \mathrm{~m}$ \\
Average heat flux $\left(q_{0}\right)$ & $17.7 \mathrm{~W} / \mathrm{m}$ & Initial point $\left(R_{g p 1} / R_{g p 2} / R_{u g}\right)$ & $0.1 / 0.2 / 0.3$ \\
\hline
\end{tabular}

\section{RESULTS}

The calculation of the penetration radii was carried out in MATLAB for the two approaches. The results that were obtained are the following:

a) Ground nodes temperature optimization: $R_{g p 1}=0.163 \mathrm{~m}, R_{g p 2}=0.362 \mathrm{~m}, R_{u g}=0.593 \mathrm{~m}$.

b) Heat transfer rate optimization: $R_{g p 1}=0.165 \mathrm{~m}, R_{g p 2}=0.352 \mathrm{~m}, R_{u g}=0.517 \mathrm{~m}$.

It can be seen that both approaches produce quite similar results for $R_{g p 1}$ and $R_{g p 2}$. However, the ground temperatures approach produces a bigger undisturbed ground radius. The results obtained by each model are shown in Figure 3, for each optimization approach.
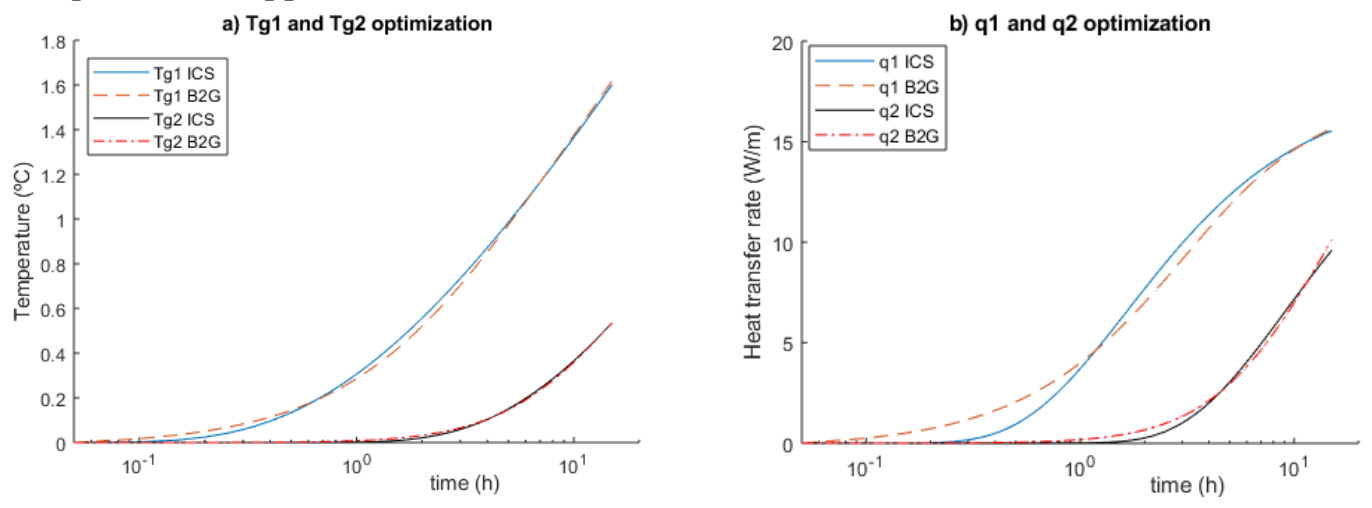

Figure 3 Penetration radii calculation: a) Ground nodes temperature optimization; b) Heat transfer rate optimization.

It can be seen that, for both cases, the results produced by the B2G model are quite similar to the results produced by the ICS model. The accuracy of these results will be validated in the next step, with the simulation of the TRT. Figure 4 shows the comparison between the outlet temperature calculated by the B2G model implemented in TRNSYS and the experimental outlet temperature for the two sets of penetration radii obtained previously.

For both optimization approaches, the calculated outlet temperature is quite similar to the experimental one, with a RMSE of $0.088 \mathrm{~K}$ in the ground temperatures approach (case a), and $0.087 \mathrm{~K}$ in the heat transfer rate approach (case b). Regarding the calculated heat transfer to the ground and the deviation with the experimental results, it is summarized in Table 2.

Table 2. Heat transferred to the ground during the TRT

\begin{tabular}{c||cc||cc}
\hline Experimental & B2G model. method a) & Percentage difference & B2G model. Method b) & Percentage difference \\
\hline \hline $43022.6 \mathrm{~kJ}$ & $41864.5 \mathrm{~kJ}$ & $-2.69 \%$ & $41932.2 \mathrm{~kJ}$ & $-2.53 \%$ \\
\hline
\end{tabular}




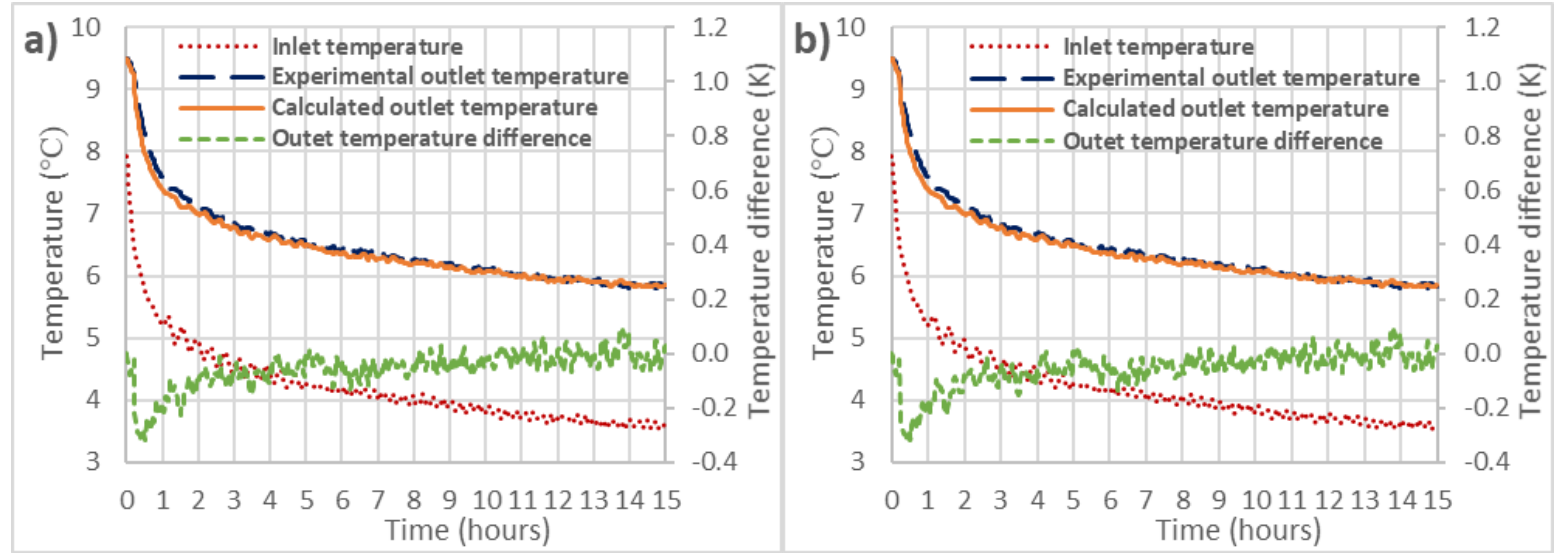

Figure 4 Comparison between the experimental and calculated outlet temperature using the B2G model with the calculated penetration radii. a) Ground nodes temperature optimization; b) Heat transfer rate optimization.

Taking a look at the results, it can be concluded that the 'heat transfer optimization approach' is slightly better.

It should be mentioned that the calculation of the ground nodes position was also carried out with different values of heat injection, producing the same optimal position of the ground nodes. Therefore, it can be concluded that this position is independent of the heat injected and can be applied in the B2G model inside a complete ground source heat pump system model, where the heat load will be variable, also along the borehole depth.

\section{CONCLUSION}

The B2G dynamic model was presented previously as an accurate tool to reproduce the short-term behavior of a BHE for different configurations (U-tube, coaxial or spiral coaxial). In this work, a new methodology to calculate the position of the three ground nodes considered in the model is presented. For this purpose, a comparison between the B2G model, adapted to a constant heat flux on the borehole wall surface, and the Infinite Cylindrical Source (ICS) is carried out to find the position of the ground nodes that reproduce with the highest accuracy the ground thermal response. In order to achieve this, two approaches were considered in the calculation of the ground nodes position, depending on the results that are compared between models. In the case a), the values to compare are the ground nodes temperatures; while in the case b), the values to compare are the heat transfer rates between ground nodes. The calculated ground nodes positions (referred as penetration radii) are used in the B2G model implemented in TRNSYS to simulate a thermal response test, reproducing the dynamic thermal response of the BHE with a high accuracy (maximum RMSE of $0.088 \mathrm{~K}$ and maximum $2.7 \%$ deviation in the calculation of the heat exchanged with the BHE). The main objective of this new methodology would be the calculation of several polynomial correlations, which would be implemented in the TRNSYS model, in order to determine the ground nodes positions depending on the ground thermal properties, the borehole geometry and the operating conditions heat injection period).

\section{ACKNOWLEDGMENTS}

The present work has been supported by the European Community Horizon 2020 Program for European Research and Technological Development (2014-2020) inside the framework of the project 656889 - GEOTeCH (Geothermal Technology for Economic Cooling and Heating) and by the Generalitat Valenciana inside the program "Ayudas para la contratación de personal investigador en formación de carácter predoctoral (ACIF/2016/131)". 


\section{REFERENCES}

Al-Khoury, R. 2012. Computational Modeling of Shallow Geothermal Systems. BocaRaton, FL, USA: CRC Press.

Bauer, D., Heidemann, W., Müller-Steinhagen and H., Diersch, H.-J. G. 2011. Thermal resistance and capacity models for borehole heat exchangers. Intenational Journal of Energy Research 35(4): 312-320.

Carslaw, H. S. and Jaeger, J. C. 1959. Conduction of heat in solids. New York, NY, USA: Oxford University Press.

Cazorla-Marin, A., Montagud, C., Witte, H., Hylkema, R. and Corberán, J.M. 2017a. Modelling and Experimental V alidation of a Novel Co-axial Spiral Borehole Heat Exchanger. IGSHPA Technical/Research Conference and Expo 2017. Denver, CO, USA. March 14-16.

Cazorla-Marin, A., Montagud, C., Corberán, J. M. and Acuña, J. 2017b. Modeling of a coaxial Borehole Heat Exchanger and experimental validation. $10^{\circ}$ Congreso Internacional Ingeniería Termodinámica 10CNIT. Lleida, Spain. June 28-30.

Cazorla-Marin, A., Montagud, C. and Corberán, J. M. 2018. Adaptation of the B2G dynamic model to new borehole heat exchanger coaxial configurations. CYTEF 2018 - IX Congreso Ibérico | VII Congreso Iberoamericano de las Ciencias y Técnicas del Frío. Accepted.

Eskilson, P. and Claesson, J., 1988. Simulation model for thermally interacting beat extraction boreholes. Numerical Heat Transfer 13(2): 149-65.

European Commision. 2015. Geothermal Technology for €conomic Cooling and Heating (H2020-LCE-2014-2, GEOTeCH656889). Available online at: http://www.geotech-project.eu/.

Hart, D. P. and Couvillion, R. 1986. Earth-Coupled Heat Transfer. Dublin, OH, Ireland: National Water Well Association

Lamarche, L., Kajl, S. and Beauchamp, B. 2010. A review of methods to evaluate borehole thermal resistances in geothermal heat-pump systems, Geothermics 39(2): 187-200.

Li, M. and Lai, C.K. 2012. New temperature response functions ( $G$ functions) for pile and borehole ground heat exchangers based on compositemedium line-source theory. Energy 38: 255-263.

MathWorks. 2017. Global Optimization Toolbox - User's Guide - MATLAB. Available online at: https://es.mathworks.com/help/pdf_doc/gads/gads_tb.pdf.

Pasquier, P. and Marcotte, D. 2012. Short-term simulation of ground heat exchanger with an improved TRCM. Renewable Energy 46: 92-99.

Rees, S. J. 2016. Advances in Ground-Source Heat Pump Systems. Duxford, UK: Elsevier / Woodhead Publishing.

De Rosa, M., Ruiz-Calvo, F., Corberán, J.M., Montagud, C. and Tagliafico, L.A. 2015. A novel TRNSYS type for short-term borehole heat exchanger simulation: B2G model. Energy Conversion and Management 100: 347-357.

Ruiz-Calvo, F., De Rosa, M., Acuña, J., Corberán, J.M. and Montagud, C. 2015. Experimental validation of a short-term Boreholeto-Ground (B2G) dynamic model. Applied Energy 140: 210-223.

Witte, H.J.L. 2012. The GEOTHEX geothermal heat exchanger, characterisation of a novel high efficiency heat exchanger design. The 12th International conference on Energy Storage (Innostock 2012). Lleida, Spain. May 16-19.

Yang, H., Cui, P. and Fang, Z. 2010. Vertical-borehole ground-coupled heat pumps: A review of models and systems. Applied Energy 87: 16-27.

Yang, W., Shi, M., Liu, G. and Chen, Z. 2012. A two-region simulation model of vertical U-tube ground heat exchanger and its experimental verification, Applied Energy 86(10): 2005-2012. 